Chapman University

Chapman University Digital Commons

Communication Faculty Articles and Research

School of Communication

$2-10-2018$

Finding Meaning at Work: The Role of Inspiring and Funny YouTube Videos on Work-Related WellBeing

Sophie Janicke-Bowles

Diana Rieger

Winston Connor III

Follow this and additional works at: https://digitalcommons.chapman.edu/comm_articles

Part of the Broadcast and Video Studies Commons, Communication Technology and New Media Commons, Experimental Analysis of Behavior Commons, Industrial and Organizational Psychology Commons, Mass Communication Commons, Organizational Behavior and Theory Commons, Organizational Communication Commons, Other Business Commons, Other $\underline{\text { Communication Commons, Other Psychology Commons, Social Media Commons, and the Social }}$ Psychology Commons 


\section{Finding Meaning at Work: The Role of Inspiring and Funny YouTube Videos on Work-Related Well-Being}

\section{Comments}

This is a pre-copy-editing, author-produced PDF of an article accepted for publication in Journal of Happiness Studies in 2018 following peer review. The final publication is available at Springer via DOI: 10.1007/ s10902-018-9959-1.

\section{Copyright}

Springer 


\section{Finding Meaning at Work: The Role of Inspiring and Funny YouTube Videos on Work-Related Well-Being}

Sophie H. Janicke-Bowles,

Phone: 714-516-5184

Email: sophie.janicke@gmail.com

Diana Rieger, 2

Email Diana.rieger@uni-mannheim.de

Winston Connor, III ${ }^{3}$

Emailwconnor@email.uark.edu

1 School of Communication, Chapman University, 1 University

Dr., Orange, CA, 92866 USA

2 Department of Media Communication Studies, University of

Mannheim, Rheinvorlandstr. 5, 68159 Mannheim, Germany

3 University of Arkansas, Fayetteville, USA

\section{Abstract}

Watching online videos on social media is a common activity in today's digital age, but its' impact on employee well-being at work has not been investigated yet. The current study tried to fill this gap by investigating the role hedonic and eudaimonic online videos play on employee's stress levels and well-being at work. An online experiment with 200 full time employees in the US was conducted exploring the role of inspiring affect and positive affect on three distinct well-being outcomes: subjective well-being, psychological well-being and social well-being at the workplace. A path model suggests unique effects for inspiring videos on indicators of subjective (vitality), psychological (meaning at work) and social (relatedness at work) well-being. In addition, appreciating the good things in life mediated the relationship between inspiring affect and 
meaning and relatedness at work. Furthermore, employees generally felt less stressed after watching any type of online video (including a non-entertaining control video), but felt the highest energy surge after watching an elevating video. Implications about the role of online videos for employees' well-being are discussed.

\section{Keywords}

Workplace well-being

Online videos

Stress

Vitality

Gratitude

\section{Introduction}

Using the web for personal purposes during work, often referred to as cyberslacking or cyberloafing, is a common phenomenon, with research indicating that approximately $70-80 \%$ of employees who use computers at work are prone to engage in this activity (Coker 2011; Garrett and Danziger 2008b). Research indicates that people cyberslack as much as $6 \mathrm{~h} 48$ min per week, which equals $1 \mathrm{~h}$ 29 min a day (D'Abate and Eddy 2007). A lot of research has focused on the negative effects of cyberloafing in the workplace (Greenfield and Davis 2002; Mastrangelo et al. 2006). Other research, however, has shown no detrimental (Garrett and Danziger 2008b) and even beneficial effects of personal web use during work, including increased productivity (Coker 2011), positive emotions (Lim and Chen 2012), alleviation from boredom, stress and greater work engagement (Garrett and Danziger 2008a; Eastin et al. 2007).

\section{$\mathrm{AQ1}$}

Coker (2011) showed in a study on office workers, that Youtube video consumption accounted for about $20 \%$ of cyberloafing in a given workday. With the average amount of 90 min of cyberloafing a day, this culminates to 19 min $(20 \%$ of this time) that adult office workers may spend on Youtube while at work. While research on the exact amount of time people spend on social media or Youtube at work is still limited, we do know that $63 \%$ of online adults across all ages use Youtube on a regular basis, and $82 \%$ of the 18-29 year olds, respectively (Anderson 2015). Thus, watching online videos has now become a common phenomenon overall, bearing 
the question about Youtube video's impact on well-being and stress reduction at the workplace in specific.

\subsection{State of the Art: Stress at Work}

According to a national representative survey of 3068 American adults $18+$ conducted by the American Psychological Association in 2014, stress levels of the average American population are 4.9 on a 10 point scale with 10 being "a great deal of stress". Specific subgroups, such as parents, women, the millennial and generation X, and households with an income of less than 50,000 per year report higher levels of stress than the average population (APA report, n.d.). Money and work are perceived as the very or somewhat significant sources of stress (64 and $60 \%$ respectively).

\section{$\mathrm{AQ} 2$}

To recover from work related stress, people engage in a variety of activities, including listening to music (44\%), exercising or walking (43\%) and watching TV or movies for more than $2 \mathrm{~h}$ a day (40\%) (APA report, n.d.). It can be argued that media use while at work may represent a form of stress management. Recent research started to explore the role media plays for recovery and stress reduction after and at work (Rieger et al. 2014, 2017; Reinecke 2009a, b; Reinecke et al. 2011). The findings indicate that interactive as well as non-interactive media (Reinecke et al. 2011), hedonic (i.e., purely pleasurable) and eudaimonic (i.e., meaningful) entertainment (Rieger et al. 2014, 2017) let people recover from stress and impact their well-being.

The research, however, is limited in several ways: (1) It mostly investigated the effects of work strain in a laboratory setting using students as participants who may suffer from work-related exhaustion in different ways than employed people do. (2) The past research differentiated broadly between hedonic and eudaimonic entertainment but failed to investigate specific media stimuli that elicit a particular set of eudaimonic experiences (i.e., elevation and gratitude) and hedonic entertainment experiences (i.e., positive affect). (3) It focused only on one specific indicator of subjective well-being, namely vitality. Some scholars, however, paint a more elaborated picture on well-being and differentiate between subjective, psychological and social dimensions of well-being (Gallagher et al. 2009; Keyes 1998). Keyes (1998) points out that the majority of well-being theories focus on the self as a private entity. However, the self is also developed and expressed in public. Thus, he argues, well-being is also a social construct which is defined by the "appraisal of one's circumstance and functioning in society" (p. 122). Based on the 
outlined limitations, our study seeks to extend this work by (a) investigating the role of specific hedonic and eudaimonic emotion inducing Youtube videos (namely gratitude and elevation) on (b) a comprehensive set of well-being indicators tapping into subjective, psychological and social well-being as well as stress reduction at (c) a workplace setting, rather than the laboratory.

\subsection{Two-Factor Model of Entertainment}

Most recently, research differentiates between two types of media entertainment (Oliver and Bartsch 2011; Vorderer 2011): hedonic media, which includes the experience of general positive affect such as pleasure, amusement and delight and the absence of negative emotions; and eudaimonic media, which captures more complex media experiences such as appreciation, feeling tender or moved and inspired (Oliver et al. 2012). More specifically, eudaimonic entertainment experiences have been measured with facets borrowed from the positive psychology literature (i.e., Ryff 1998) such as purpose in life, autonomy, competence, growth, relatedness and the activation of central values (Wirth et al. 2012). On the other hand, hedonic entertainment has been measured with concepts such as feeling entertained, having had fun and feeling pleasure (Wirth et al. 2012). Gall Myrick (2015) found that, for example, internet cat videos are not only enjoyable to watch, but also elicit hedonic positive emotions such as feelings of happiness and contentment, as well as increased energy after viewing.

$\mathrm{AQ3}$

Rieger et al. $(2014,2017)$ were the first that investigated the role of eudaimonic and hedonic media experiences on well-being and recovery from stress in a laboratory setting. However, the researchers did not further differentiate between eudaimonic and hedonic media content on well-being, as eudaimonic entertainment is only a collective term for a huge variety of content that can be described as meaningful or inspiring.

Recently, many studies concentrated on elevation as one very prototypical eudaimonic media experience. Elevation is associated with mixed affect (which includes feeling happy and sad at the same time) as well as feeling moved, tender, touched and has been associated with physiological indicators such as feeling a lump in the throat and a warmth in the chest (Oliver et al. 2012; Haidt 2003). It is elicited when witnessing acts of moral beauty, such as altruism and kindness and motivates to emulate the virtuous behavior and act prosocially (Algoe and Haidt 2009; Freeman et al. 2009). For example, Oliver et al. (2012) found that feeling elevated from recalling a meaningful movie motivated people to become a better 
person and seek what really matters in life. This effect of meaningful movies seems to be based on the activation of collectivist values (such as tradition) and universal values (such as benevolence) which in turn, fostered a feeling of elevation and moral intentions (Oliver et al. 2012; Rieger et al. 2016).

Additionally, gratitude, which is defined as an appreciation for the positive in the world and the good things that happen in life (Park et al. 2004; Wood et al. 2010), has also been associated with generally greater well-being and greater helping behavior (Bartlett and DeSteno 2006). Even though research so far lacks in investigating gratitude as an eudaimonic media experience, some research findings suggest that elevating videos also elicit gratitude. For example, Algoe and Haidt (2009) found that participants exposed to an elevation video experienced greater warmth and gratitude, in addition to elevation, compared to an admiration and fun video. Diessner et al. (2013) report the same findings with another elevating video. Consequently, we assume that eduaimonic entertainment can indeed elicit gratitude in addition to elevation and that these experiences may have the potential for effects even beyond the affective experience-namely effects on well-being.

Thus far, research on the effects of hedonic and eudaimonic entertainment on stress reduction and well-being is limited by focusing only on entertainment experiences, rather than specific affective experiences. However, in order to make predictions about specific effects of online video consumption on work related well-being outcomes, it is important to explore such facets in more detail. Consequently, the current study focused on elevation and experiences of gratitude as specific affective expressions of eudaimonic entertainment and positive affect as an expression of hedonic entertainment. We predicted:

H1a Eudaimonic Youtube videos will predict elevation and gratitude experiences.

H1b Hedonic Youtube videos will predict positive affect.

\subsection{Theories of Well-Being}

The distinction between hedonic and eudaimonic media experiences (cf. Oliver and Raney 2011; Oliver and Bartsch 2011) conceptually overlaps with the distinction between different forms of well-being. That is, whereas subjective well-being has been conceptualized as the maximization of pleasure or positive affect, the minimization of unpleasant states and satisfaction with life (Ryan and Deci 2001; Diener 1984), psychological well-being involves actions that lead to personal growth, meaningfulness, positive relationships, environmental mastery, self- 
acceptance and purpose in life (Deci and Ryan 2002; Ryff 1989). Similarly, hedonic entertainment has been defined to include aspects of subjective well-being including positive affect and low negative affect, and eduaimonic entertainment has been defined to include aspects of psychological well-being including the search for meaning and purpose in life (Oliver and Bartsch 2011; Oliver and Raney 2011).

Additionally, Keyes (1998) introduced and demonstrated social well-being to be a third dimension of well-being including the factors of social acceptance, social actualization, social coherence, social contribution, and social integration. Gallagher et al. (2009) could show that a hierarchical model including hedonic, eudaimonic, and social well-being captures the many aspects of well-being (14 first order factors) the best.

While Rieger et al. (2014) started to explore the relationship between hedonic and eudaimonic entertainment experiences and vitality as an indicator of subjective well-being, Oliver et al. (2012) found a relationship between eudaimonic media and the motivation to be a better person, which can be seen as an attribute of psychological well-being (to grow as a person). Also, Oliver and Bartsch (2011) argue that eudaimonic media is contributing to understanding one's life purpose, and finding meaning in one's life, which again is a concept of psychological wellbeing. Additionally, research indicated that psychological well-being (living life to the fullest; Emmons and McCullough 2003; Seligman et al. 2005) as well as subjective well-being are enhanced with increased gratitude levels. In the work context, research has related gratitude to, for example, job satisfaction (Lanham et al. 2012) and employee subjective well-being (Chancellor et al. 2015; Kaplan et al. 2014). The research findings indicate a close relationship between eudaimonic entertainment - with elevation and gratitude being the particular affective manifestations in our case - and psychological well-being indicators including purpose in life, self-growth and meaning in life. Applied to the work context, finding meaning in one's work is defined as experiencing work as significant and positive in valence whereas this positive valence is growth and purpose oriented (eudaimonic focus) rather than pleasure oriented (hedonic focus) (Steger et al. 2012). Consequently, perceiving one's work as meaningful can be seen as a facet of psychological well-being and, in fact, research has shown a clear relationship between meaning at work and psychological well-being (Arnold et al. 2007). Thus, we predicted that eudaimonic entertainment experiences (elevation and gratitude) would positively contribute to employees perceived meaning at work.

H2 Elevation and gratitude will predict meaning at work. 
Additionally, according to Self-Determination Theory (Deci and Ryan 2000), competence, autonomy and relatedness are three universal psychological basic needs that together are a major contributor to psychological well-being. Relatedness is conceptualized as the need to have secure and close human connections and multiple studies point towards the importance of relationships and connectedness with others for well-being (i.e., Fredrickson et al. 2008). In the work context, relatedness as defined in this study, is concerned with establishing relationships with others and mutual respect with one's coworkers (Baard et al. 2004). Research shows that the satisfaction of relatedness, autonomy and competence (also referred to as intrinsic needs) at work, further predicts performance at the job and psychological adjustment (including the absence of depression, anxiety, somatic symptoms and social dysfunction; Baard et al. 2004). Additionally, the satisfaction of these intrinsic needs has been associated with eudaimonia, or psychological wellbeing, rather than subjective well-being (Ryan et al. 2008). Gallagher et al. (2009), however, sees relatedness, or the need to have close and meaningful relationships with others, as a separate well-being construct, namely social well-being. In the current study we build on Gallagher et al.'s (2009) work and assume that elevation and gratitude as elicited from eudaimonic media predict relatedness at work as an indicator of social well-being. Additionally, based on research investigating the impact of daily (mood) fluctuations for well-being (Reis et al. 2000), we expected a positive relationship between positive affect and relatedness at work. AQ4

H3a Elevation and gratitude will predict relatedness at work.

H3b Positive affect will predict relatedness at work.

Moreover, as outlined earlier, gratitude has been defined as appreciation for the positive things in life. Adler and Fagley (2005) define appreciations as "acknowledging the value and meaning of something - an event, a person, a behavior, an object - and feeling a positive emotional connection to it." (Adler and Fagley 2005, p. 81). Appreciation has state and trait qualities and Adler and Fagley (2005) differentiate eight aspects of appreciation including a focus on what one has ("have" focus), awe (emotional connection to something larger than ourselves), ritual (performing acts of appreciation), present moment (connection to and savoring of the present moment), self/social comparison (appreciation one has after comparing oneself to previous situations (self) that were worse than the present, or other people (social) that have it worse than we do), gratitude (thankfulness toward 
a benefactor), loss/adversity (realizing that one cannot take things for granted), and interpersonal appreciation (acknowledging the positive impact of relationships on our lives). We choose to use the have focus component for our study, which includes "noticing, acknowledging, and feeling good about (i.e., appreciating) what we have in our lives" (p. 82), because (1) it was the second highest scoring subscale in Adler and Fagley's (2005) study, after gratitude, indicating its relevance among the appreciation concept, and (2) it is a broad enough concept to apply to various circumstances employees might feel appreciation for, compared to gratitude appreciation, which involves a specific appreciation toward a benefactor, which also cannot be elicited as such from media stimuli (see Algoe and Haidt 2009). Adler and Fagley (2005) outline that appreciation can be elicited through external triggers, such as events that "spontaneously and unintentionally evoke appreciation" (p. 85). We think that such an event could be a media stimulus, such as an online video watched at work, which elicits feelings of thankfulness and elevation. The researchers also found that appreciation predicted life satisfaction, positive affect and negative affect, even after controlling for optimism, spirituality and emotional self-awareness (Adler and Fagley 2005). Consequently, appreciation is related to subjective well-being, and therefore could be a relevant variable to explain the effects of entertaining video exposure on well-being indicators at the workplace.

Additionally, Sheldon and Lyubomirsky (2006) argued that gratitude could foster reinterpreting negative situations, such as work stress for example, to see them in a positive light. A highly demanding job could be seen as an opportunity to grow and the annoying task ahead may, overall, be not as bad after all. Thus, gratitude could also trigger the meaningfulness of a situation. That is, accompanying gratitude is a positive mood state, which could foster this reinterpretation or shift in focus towards the positive and appreciation of the good things, to avoid cognitive dissonance (Festinger 1957). Additionally, Lambert et al. (2009) showed that trait gratitude predicts positive reframing of a situation (i.e., seeing something that was previously perceived as negative in a positive light), which in turn predicts social coherence (social well-being indicator, c.f., Gallagher et al. 2009). The authors argue, in line with Fredrickson's broaden-and-build perspective (2001), that their results could also be interpreted from a state perspective, in that accumulated grateful states resulting from a series of positive reframes might over time build social coherence. Even though we only rely on a single exposure in our experiment, we hypothesize:

H4 Elevation and gratitude experience will predict have focus (appreciation for the good things in life). 
H5 Have focus (appreciation for the good things in life) will mediate the relationship between elevation and gratitude as elicited from eudaimonic Youtube videos and (a) meaning at work and (b) relatedness at work.

Elevation and gratitude count towards a specific category of positive emotions, which have been linked to a distinct openness to others and loss of ego concerns (Haidt and Morris 2009; Algoe and Haidt 2009). Self-transcendent emotions, as they are referred to, open people's viewpoint to recognize and understand their current situation from a broader perspective of life, help them find meaning and purpose in life and draw them out of their usual state of consciousness (Haidt and Morris 2009). These self-transcendent emotions, which, in addition to elevation and gratitude, also include admiration, and compassion (cf. Algoe and Haidt 2009; Haidt 2003; Haidt and Morris 2009) are different from purely hedonic emotions, such as joy and pleasure, which, in turn, do concern the self.

Because experiencing self-transcendent emotions can direct one's focus toward the bigger picture of life, we expected that such media experiences (also referred to as inspiring affect), compared to positive affect, will predict the psychological wellbeing indicator of meaning at work, as outlined above. In contrast, positive affect, which is one element of subjective well-being, may be conceptually more closely related to vitality - a positive sense of energy, aliveness and enthusiasm (Ryan and Frederick 1997). Following the definition of subjective well-being that focuses on satisfaction with life and maximization of pleasure, it would be reasonable to predict a relationship between media induced positive affect and vitality as an indicator for subjective well-being. On the other hand, Rieger et al. (2014) found a significant correlation between eudaimonic media experiences and vitality as well. However, from a theoretical perspective, we would not expect eudaimonic media to directly predict a subjective well-being indicator such as vitality, which is mainly concerned with maximizing pleasure, momentary satisfaction and a sense of aliveness. However, it may be that eudaimonic media, which, is more complex and demanding in nature leads to a feeling of increased arousal and energy after successfully mastering that experience. In fact, Huta and Ryan (2010) found that trait eudaimonia is related to vitality and Rieger et al. (2017) found that a hedonically negative movie scene rather than a positive one increased vitality. Consequently, based on the theoretical conceptualization and the research findings outlined, we posed the following hypotheses:

H6a Positive affect will predict vitality. 
H6b Elevation and gratitude will predict vitality.

Lastly, Rieger et al. (2014) demonstrated that vitality is an indicator for a successful recovery from stress. Similarly, Reinecke et al. (2011) found that playing the game World of Goo or watching a clip of someone playing the game or a funny animated Youtube video lead to recovery from stress as well as increased vitality afterwards. What is missing from this research is a pre-post assessment of stress reduction and vitality increase in relation to the interaction of different forms of videos at a workplace setting. We expected that in order for media to alleviate stress, it has to elicit some form of entertainment experience (as compared to media not fostering much entertainment experience). Consequently, we predicted that an uninvolving media stimulus (such as a slide presentation of nature pictures, without a storyline or narrative) will contribute less to stress reduction and vitality increase for employees, compared to entertaining hedonic or eudaimonic media content. That is because entertaining media is transporting in nature (Green et al. 2004), which absorbs the audience into the storyline and thus, could potentially be more restorative than a non-narrative media exposure (Rieger and Bente, in press). Based on Attention Restoration Theory (Kaplan 1995), that posits a restorative effect of nature exposure, it follows that exposure to nature slides would by its' nature be stress reducing as well. However, in the current study, we were particularly interested in the effects of entertaining media (which includes media characters and a storyline) on stress reduction and recovery, rather than the effects of general media exposure (i.e., slides, music, posters) versus no media exposure. Thus, we predicted:

H7a People will feel significantly less stressed after the eudaimonic or hedonic media conditions compared to people in the control condition.

$\boldsymbol{H}_{7} \boldsymbol{b}$ People will feel significantly more vitality after the eudaimonic and hedonic videos compared to people in the control condition.

With regard to the specific effects of eudaimonic and hedonic entertainment on stress reduction and vitality increase, we do not have a detailed empirical basis to make specific predictions. As outlined earlier, Rieger et al. (2014) showed direct correlations between vitality and both, hedonic and eudaimonic media. On the other hand, from a theoretical perspective of the theory of subjective well-being, we could expect greater vitality increase from hedonic media. Based on the limited research we posed the research question: 
RQ: What unique role does hedonic and eudaimonic videos play for stress reduction and vitality?

The derived hypotheses and research question were tested in a 4 factorial online experiment of office workers across the US, who were exposed to either an elevating, gratitude inducing, funny or control (slide show) video condition. Their stress level and vitality was measured before and after the video exposure along with our dependent variables (see below).

\section{Method}

\subsection{Demographics}

The sample of $N=200$ full time employees consisted of $48 \%$ females, $51.5 \%$ males and $0.5 \%$ transgendered and was equally distributed between conditions, $\chi^{2}(3)=5.31, p=.540$. Participants' ages ranged between 20 and 68 years $(M=37.11, S D=11.05)$ with $63.5 \%$ Caucasian/White, $15.5 \%$ African American/Black, 12.5\% Hispanic/Latin American, 5\% Asian/Pacific Islander, 1.5\% Native American/American Indian participants, and 2\% responded as other. In a regular work-week, the majority of respondents (55\%) indicated that they worked between 40 and $50 \mathrm{~h}$ per week. Additionally, a large majority of the sample (84\%) indicated that they watched online videos for fun during work. More specifically, $30.5 \%$ indicated to watch online videos approximately 1-2 times a week, 20\% indicated to watch them 3-4 times a week, 18\%, 5-6 times a week and $15.5 \%$ said they would watch online videos all the time.

\subsection{Pretest}

To select the videos for the main study a pretest was employed to select videos that elicit eudaimonic and hedonic entertainment experiences, namely gratitude, elevation and fun. We relied on the different forms of affective responses as research has indicated that eudaimonic and hedonic media can be discriminated based on distinct affective responses (i.e., Oliver et al. 2012).

A total of 24, 3-5 min videos were selected for the pretest, 18 based on their theoretical ability to elicit eudaimonic feelings of awe, ${ }^{1}$ gratitude, and elevation; and six for their hedonic nature (referred to as "fun" videos). Using Qualtrics, six blocks were created, each containing four of the 24 videos, which were equally randomized between participants. Each participant was exposed to 4 videos in random order. 
A total of $N=102$ participants recruited from introductory courses at a university setting took part in the pretest ( $58 \%$ female, $M_{\text {age }}=19.22 S D_{\text {age }}=1.68$ ) for the exchange of extra credit. After each video, participants responded to positive affect, elevation, gratitude and physiological indicator subscales adapted from Oliver et al. (2012) and McCullough, Tsang and Emmons (2004) on a 7-point scale from 1 "not at all" to 7 "very much". Even though the physiological indicators were only subjective assessments, rather than actual biomarkers, they helped us to distinguish inspiring from purely funny content (see Oliver et al. 2012) as an additional dimension besides emotional valence. The videos with the highest respective emotional scores one each scale and lowest on the other two, in combination with the physiological indicators were selected for the main study. A post hoc power analysis using $\mathrm{G}^{*}$ Power (Faul et al. 2007) on the mean difference between the 6 video conditions on gratitude with $\alpha=.05, N=102$, number of group $=6$, calculated effect size $f=.62$, results in high power $(1-\beta=.999$, critical $F$ (5, $96)=2.30$ noncentrality parameter $\delta=39.32$ ), supporting the validity of our results.

The results indicated that none of the gratitude videos was significantly greater in experiences of gratitude compared to elevation. However, the elevation videos showed a significant higher score for elevation only compared to the gratitude videos (see Table 1), indicating that videos can elicit elevation only, without feelings of gratitude. A series of $t$ tests on each video per condition indicated no significant difference between both fun videos on positive affect, both gratitude videos on the experience of gratitude, and both elevation videos on the experience of elevation. Consequently, we combined the two videos per condition for the analysis. Table 1 summarizes the results of the pretest for the selected videos.

\section{Table 1}

Means, standard deviations and corresponding significant $t$ test result for pretest videos

\begin{tabular}{|c|c|c|c|c|c|c|}
\hline Videos & Minutes & $\begin{array}{l}\text { Gratitude } \\
M(S D)\end{array}$ & $\begin{array}{l}\text { Elevation } \\
M(S D)\end{array}$ & $\begin{array}{l}\text { Positive } \\
\text { affect } \\
M(S D)\end{array}$ & $\begin{array}{l}\text { Hedonic } \\
\text { physio. } \\
M(S D)\end{array}$ & $\begin{array}{l}\text { Eudaimonic } \\
\text { physio. } \\
M(S D)\end{array}$ \\
\hline
\end{tabular}

Hedonic physio. hedonic physiological indicators, Eudaimonic physio. eudaimonic physiological indicators (cf. Oliver et al. 2012). A separate dependent t test was conducted for the hedonic and eudaimonic physiological indicators. See "Appendix" for the list of videos

$* * p<.001 ; * p<.05$

Different superscripts within rows indicate significant differences between emotions within each experimental condition on $p<.05$ 


\begin{tabular}{|l|l|l|l|l|l|l|}
\hline Videos & Minutes & $\begin{array}{l}\text { Gratitude } \\
\boldsymbol{M}(\mathbf{S D})\end{array}$ & $\begin{array}{l}\text { Elevation } \\
\boldsymbol{M}(\mathbf{S D})\end{array}$ & $\begin{array}{l}\text { Positive } \\
\text { affect } \\
\boldsymbol{M}(\mathbf{S D})\end{array}$ & $\begin{array}{l}\text { Hedonic } \\
\text { physio. } \\
\boldsymbol{M}(\mathbf{S D})\end{array}$ & $\begin{array}{l}\text { Eudaimonic } \\
\text { physio. } \\
\boldsymbol{M}(\mathbf{S D})\end{array}$ \\
\hline $\begin{array}{l}\text { Gratitude1 } \\
(n=20)\end{array}$ & 3.02 & $\begin{array}{l}5.28 \\
(1.48)^{\mathrm{a}}\end{array}$ & $\begin{array}{l}5.52 \\
(1.56)^{\mathrm{a}}\end{array}$ & $\begin{array}{l}3.95 \\
(1.65)^{\mathrm{b}}\end{array}$ & $\begin{array}{l}2.23 \\
(1.12)\end{array}$ & $\begin{array}{l}3.74 \\
(1.34)^{* *}\end{array}$ \\
\hline $\begin{array}{l}\text { Gratitude2 } \\
(n=15)\end{array}$ & 3.5 & $\begin{array}{l}5.05 \\
(1.72)^{\mathrm{a}}\end{array}$ & $\begin{array}{l}5.55 \\
(1.49)^{\mathrm{a}}\end{array}$ & $\begin{array}{l}3.61 \\
(1.63)^{\mathrm{b}}\end{array}$ & $\begin{array}{l}2.01 \\
(1.23)\end{array}$ & $\begin{array}{l}3.81 \\
(1.43)^{* *}\end{array}$ \\
\hline $\begin{array}{l}\text { Elevation1 } \\
(n=15)\end{array}$ & 4.27 & $\begin{array}{l}4.42 \\
(1.78)^{\mathrm{a}}\end{array}$ & $\begin{array}{l}5.56 \\
(1.72)^{\mathrm{b}}\end{array}$ & $\begin{array}{l}3.83 \\
(1.48)^{\mathrm{c}}\end{array}$ & $1.90(1.19)$ & $\begin{array}{l}3.14 \\
(1.41)^{* *}\end{array}$ \\
\hline $\begin{array}{l}\text { Elevation2 } \\
(n=20)\end{array}$ & 3.14 & $\begin{array}{l}4.06 \\
(1.39)^{\mathrm{a}}\end{array}$ & $\begin{array}{l}5.26 \\
(1.42)^{\mathrm{b}}\end{array}$ & $\begin{array}{l}3.82 \\
(1.86)^{\mathrm{a}}\end{array}$ & $\begin{array}{l}2.65 \\
(1.53)\end{array}$ & $3.96(1.49)^{*}$ \\
\hline $\begin{array}{l}\text { Funny1 } \\
(n=12)\end{array}$ & 3.34 & $\begin{array}{l}2.44 \\
(1.36)^{\mathrm{a}}\end{array}$ & $\begin{array}{l}2.17 \\
(1.42)^{\mathrm{a}}\end{array}$ & $\begin{array}{l}4.50 \\
(1.66)^{\mathrm{b}}\end{array}$ & $\begin{array}{l}3.12 \\
(1.36)^{*}\end{array}$ & $1.98(1.31)$ \\
\hline $\begin{array}{l}\text { Funny2 } \\
(n=20)\end{array}$ & 3.25 & $\begin{array}{l}3.30 \\
(1.66)^{\mathrm{a}}\end{array}$ & $\begin{array}{l}3.23 \\
(1.42)^{\mathrm{a}}\end{array}$ & $\begin{array}{l}5.00 \\
(1.52)^{\mathrm{b}}\end{array}$ & $\begin{array}{l}4.32 \\
(1.55)^{*}\end{array}$ & $3.39(1.82)$ \\
\hline
\end{tabular}

Hedonic physio. hedonic physiological indicators, Eudaimonic physio. eudaimonic physiological indicators (cf. Oliver et al. 2012). A separate dependent t test was conducted for the hedonic and eudaimonic physiological indicators. See "Appendix" for the list of videos

$* * p<.001 ; * p<.05$

a,b,c Different superscripts within rows indicate significant differences between emotions within each experimental condition on $p<.05$

AQ5

\subsection{Procedure}

An experimental design with four conditions was employed to test our predictions about the effects of online videos at the workplace on recovery experience and work well-being. A Qualtrics online panel was conducted recruiting a sample of $N=200$ full-time employees over the course of 1 week. Respondents have been at their job with a median length of 2-4 years and the majority of the respondents $(60 \%)$ made between $\$ 50,000$ and $\$ 200,000$ per year (before taxes). Over half of the respondents $(56.5 \%)$ had a Bachelor degree or higher (Master's, Doctorate) and worked in white collar jobs $(74 \%)$.

Participants were screened to only take the survey when they were at work and when they had worked for at least $4 \mathrm{~h}$ without a break to ensure a minimum of work strain, and had audio and visual capabilities on their computer. In our follow up question, $34 \%$ of the participants indicated to have worked for $4 \mathrm{~h}$ and $61 \%$ over $4 \mathrm{~h}$ 
before taking the survey. Five percent of the sample indicated that they actually worked less than $4 \mathrm{~h}$ before taking the survey, in contrast to their previous indication. We investigated our analyses with and without those participants in our sample, and did not find any differences, which is why we included them in our final sample.

Participants did not have the opportunity to fast forward or skip the video and were instructed to watch the video completely. $11 \%(n=22)$ of the sample indicated that they did something besides watching the video (e.g., eating, checking phone or smoking). The subsequent analyses did not find any difference in the entertainment experiences between the people that indicated to have multitasked compared to others. Participants were randomly assigned to one of the four experimental conditions: (a) one of two elevating videos $(n=52)$, (b) one of two gratitude videos $(n=39)$, (c) one of two funny videos $(n=51)$, (d) a control video condition $(n=58)$. Participants within each condition randomly saw one of the two videos. Participants in the control condition watched a 4-min long slideshow of different nature scenes with music (based on Rieger and Bente, in press), but without any narrative or storyline. All videos lasted approximately 4 min and were downloaded from Youtube and presented without advertising pop-ups. Before watching the video, participants provided their demographics and current state of stress. After the video, participants' entertainment experiences, life appreciation (have focus), levels of stress, and well-being states (vitality, meaning at work, and relatedness at work) were assessed.

\subsection{Measures}

\subsubsection{State of Stress}

Participants stress levels before and after the video were measured with two items: "Right now, my level of stress is low (0)-high (100)," and "Right now, my level of breathing is deep and slow (0)-shallow and fast (100)." The latter item assessed the subjective physiological state of stress which is associated with shallow breathing (Conrad et al. 2007). Both items correlated highly with each other and thus, were combined to one measure of state of stress $(\mathrm{t} 1: r=.627, p<.001 ; \mathrm{t} 2: r=.644$, $p<.001)$.

\subsubsection{Positive and Negative Affect}

To measure positive and negative affect, eight items were adapted from Oliver et al. (2012), whereas four items measured positive affect (cheerful, happy, upbeat, 
joyful, $\alpha=.868$ ) and four items negative affect (sad, gloomy, depressed, melancholy, $\alpha=.816$ ).

\subsubsection{Entertainment Experiences}

Elevation To measure elevation 7 items from Oliver et al. (2012) were used $(\alpha=.931)$. Example items are: "The video made me feel touched," "The video made me feel moved".

Gratitude Gratitude was assessed with 6 items from McCullough et al.'s (2004) state gratitude scale $(\alpha=.916)$. An example item is: "The video made me feel a warm sense of appreciation."

Have focus To measure appreciation for the good things in life, the "Haves" subscale from the appreciation scale by Adler and Fagley (2005) was adapted to the context of video exposure (i.e., "The video made me notice and acknowledge the good things I get in life"). The five items held together well $(\alpha=.956)$.

Vitality Following Rieger et al. (2014), vitality was assessed with five items from the tiredness subscale of the Activation-Deactivation-Checklist (Thayer 1989). Participants were asked to indicate to what extent they felt sleepy, tired, drowsy, wide-awake, and wakeful at the moment. Negative items were reversely coded so that higher scores represented higher levels of energy and wakefulness $(\alpha=.913)$.

Meaning at work The work and meaning inventory, by Steger et al. (2012) was used to assess the amount of meaning people experience at their work. The scale consists of 10 items that all held together well (i.e., "I have found a meaningful career", "My work helps me better understand myself", $\alpha=.896)$.

Relatedness at work To measure the extent to which people feel connected to their colleagues at work, the relatedness subscale from the basic psychological needs at work scale by Baard et al. (2004) was used. Relatedness at work is concerned with establishing reliance with others and mutual respect (Baard et al. 2004). This scale consisted of eight items with sufficient reliability $(\alpha=.755)$. Sample items are: "I really like the people I work with." and "I get along with people at work."

\section{Results}

\subsection{Manipulation Checks}


Prior to testing our hypotheses, a manipulation check was conducted to test whether the experimental manipulation of inducing different levels of affect was successful. A series of ANOVA analyses across conditions with the combined two videos indicated that the gratitude and elevation media condition differed significantly from the fun and control condition in their experiences of elevation and gratitude. For positive affect, all three conditions differed significantly from the control condition. The fun condition differed significantly from the control group in positive affect, however not from the gratitude or elevation condition. Additionally, the elevation and gratitude condition did not differ significantly in their experience of positive affect. Furthermore, the analysis revealed only a marginally significant ANOVA result for negative affect, indicating only a significant difference between the gratitude and fun condition. Lastly, because there was no significant difference between the elevation and gratitude media condition in their experiences of elevation and gratitude, the conditions were combined to form a single inspiring media condition with $n=91$ (see Tables 2,3 ). Within the inspiring media condition, a significant difference remained between the experiences of elevation $(M=6.01$, $S D=.983)$ and gratitude $(M=5.82, \mathrm{SD}=.988)$ [paired $t(90)=2.69, p=.008$ ]

However, the elevation and gratitude experiences correlated very strongly with each other $(r=.775, p<.001)$ leading to multicollinearity in our path model.

Consequently, we built a combined elevation and gratitude experience score and referred to it as inspiring affect (13 items, $\alpha=.957){ }^{2}$ Importantly, inspiring affect was significantly different between the inspiring media condition and the fun and control condition. However, positive affect, was only significantly different between the inspiring and the control condition but not between the inspiring and fun condition, and negative affect was only significantly different between the inspiring and fun condition, indicating a unique feature of inspiring media experiences (see Table 3). Caveats and implications about the overlap in the emotional experience of positive affect between the inspiring and the fun condition are elaborated in Sect. 4.

\section{Table 2}

Means and standard deviations separated by experimental condition and between group ANOVA results

Video condition

Emotion

\section{Video condition}

\begin{tabular}{|l|l|l|l|}
\hline Elevation & Gratitude & Fun & Control \\
\hline $\begin{array}{l}M(S D) \\
n=\mathbf{5 2}\end{array}$ & $\begin{array}{l}M(S D) \\
n=\mathbf{3 9}\end{array}$ & $\begin{array}{l}M(S D) \\
n=\mathbf{5 1}\end{array}$ & $\begin{array}{l}M(S D) \\
n=\mathbf{5 8}\end{array}$ \\
\hline
\end{tabular}

Univariate $\boldsymbol{F}$

\begin{tabular}{l|l|l}
$\boldsymbol{F}(3,194)$ & $\boldsymbol{p}$ & $\eta^{2}$
\end{tabular} 
Video condition

Univariate $F$

\begin{tabular}{|c|c|c|c|c|c|c|c|}
\hline \multirow{2}{*}{ Emotion } & Elevation & Gratitude & Fun & Control & \multirow{2}{*}{$F(3,194)$} & \multirow[b]{2}{*}{$p$} & \\
\hline & $\begin{array}{l}M(S D) \\
n=52\end{array}$ & $\begin{array}{l}M(S D) \\
n=39\end{array}$ & $\begin{array}{l}M(S D) \\
n=51\end{array}$ & $\begin{array}{l}M(S D) \\
n=58\end{array}$ & & & \\
\hline Elevation & $\begin{array}{l}6.11 \\
(.763)^{\mathrm{a}}\end{array}$ & $\begin{array}{l}5.87 \\
(1.21)^{\mathrm{a}}\end{array}$ & $\begin{array}{l}4.69 \\
(1.43)^{b}\end{array}$ & $\begin{array}{l}4.49 \\
(1.24)^{b}\end{array}$ & 24.33 & .000 & .271 \\
\hline Gratitude & $\begin{array}{l}5.79 \\
(.889)^{\mathrm{a}}\end{array}$ & $\begin{array}{l}5.86 \\
(1.11)^{\mathrm{a}}\end{array}$ & $\begin{array}{l}5.01 \\
(1.55)^{b}\end{array}$ & $\begin{array}{l}4.75 \\
(1.17)^{b}\end{array}$ & 10.59 & .000 & .139 \\
\hline $\begin{array}{l}\text { Positive } \\
\text { affect }\end{array}$ & $\begin{array}{l}5.49 \\
(1.28)^{\mathrm{a}}\end{array}$ & $\begin{array}{l}5.29 \\
(1.47)^{\mathrm{a}}\end{array}$ & $\begin{array}{l}5.43 \\
(1.34)^{\mathrm{a}}\end{array}$ & $\begin{array}{l}4.46 \\
(1.18)^{b}\end{array}$ & 7.50 & .000 & .103 \\
\hline $\begin{array}{l}\text { Negative } \\
\text { affect }\end{array}$ & $\begin{array}{l}3.24 \\
(1.57)^{\mathrm{a}}\end{array}$ & $\begin{array}{l}3.64 \\
(1.78)^{\mathrm{a}}\end{array}$ & $\begin{array}{l}2.72 \\
(1.58)^{b}\end{array}$ & $\begin{array}{l}3.23 \\
(1.40)^{\mathrm{a}, \mathrm{b}}\end{array}$ & 2.61 & .053 & .038 \\
\hline
\end{tabular}

The significance value has been Least Significant Difference (LSD) and Games-Howell adjusted depending on the non-homogeneity of variance

Different superscripts $\left({ }^{a}, \mathrm{~b}\right)$ within rows indicate significant differences between conditions at $p<.05$. Same superscripts within rows indicate no significant difference between conditions. Levene's statistic was significant for the elevation and gratitude experiences, thus Games-Howell adjustment was used. The univariate statistics were also associated with a significant Multivariate MANOVA: $F(9,588)=11.16, p<.001$, $\eta^{2}=.15$. No interaction effects were observed

\section{Table 3}

Means and standard deviations separated by experimental condition after combining inspiring media conditions and inspiring affect, and between group ANOVA results

\begin{tabular}{|c|c|c|c|c|c|c|}
\hline \multirow{3}{*}{ Emotion } & \multicolumn{3}{|c|}{ Video condition } & \multicolumn{3}{|c|}{ Univariate $F$} \\
\hline & Inspiring & Fun & Control & \multirow[b]{2}{*}{$F(2,197)$} & \multirow[b]{2}{*}{$p$} & \multirow[b]{2}{*}{$\eta^{2}$} \\
\hline & $\begin{array}{l}M(S D) \\
n=91\end{array}$ & $\begin{array}{l}M(S D) \\
n=51\end{array}$ & $\begin{array}{l}M(S D) \\
n=58\end{array}$ & & & \\
\hline Inspiring affect & $5.92(.928)^{\mathrm{a}}$ & $4.84(1.46)^{b}$ & $4.61(1.15)^{b}$ & 27.73 & .000 & .220 \\
\hline Positive affect & $5.41(1.36)^{\mathrm{a}}$ & $5.43(1.34)^{\mathrm{a}}$ & $4.46(1.18)^{b}$ & 11.02 & .000 & .101 \\
\hline Negative affect & $3.41(1.67)^{\mathrm{a}}$ & $2.72(1.58)^{b}$ & $3.22(1.40)^{\mathrm{a}, \mathrm{b}}$ & 3.20 & .043 & .031 \\
\hline
\end{tabular}

The significance value has been Least Significant Difference (LSD) and Games-Howell adjusted depending on the non-homogeneity of variance 
Video condition

Emotion

\begin{tabular}{|l|l|l|l|l|}
\hline Inspiring & Fun & Control & & \\
\hline $\begin{array}{l}M(S D) \\
n=91\end{array}$ & $\begin{array}{l}M(S D) \\
n=51\end{array}$ & $\begin{array}{l}M(S D) \\
n=58\end{array}$ & $F(2,197)$ & $p$ \\
\hline
\end{tabular}

Different superscripts $\left({ }^{a, b, c}\right)$ within rows indicate significant differences between conditions at $p<.05$. Same superscripts within rows indicate no significant differences between conditions. Levene's statistic was significant for inspiring affect, thus GamesHowell adjustment was used. The univariate statistics were also associated with a significant Multivariate MANOVA: $F(6,392)=14.73, p<.001, \eta^{2}=.18$. No interaction effects were observed

\subsection{Hypotheses Analyzes}

To test our hypotheses 1-6 a path analysis using MPlus 5.2 statistical package was conducted using the maximum likelihood method. The predicted model yielded unsatisfactory fit to the data. The modification indices suggested an additional path between inspiring affect and positive affect. With previous research suggesting a similar relationship between inspiration and activation and positive valence (Thrash and Elliot 2004), the addition of this path was reasonable. Adding this path resulted in adequate model fit (see Fig. 1): $\chi^{2}=10.951, d f=13, \mathrm{CMIN} / d f=.84, p=.614$, RMSEA $=.000,90 \%$ CI $[.000 .060], \mathrm{CFI}=1.00, \mathrm{SRMR}=.037$. As predicted, the inspiring video condition predicted inspiring affect $(\beta=.464, p<.001)$ and the fun condition predicted positive affect supporting $\mathrm{H} 1 \mathrm{a}$ and $\mathrm{H} 1 \mathrm{~b}(\beta=.275, p<.001)$. In addition, as indicated by the modification indices, inspiring affect predicted positive affect $(\beta=.793, p<.001)$. Furthermore, inspiring affect predicted meaning at work directly $(\beta=.172, p=.027)$ supporting $\mathrm{H} 2$, but not relatedness at work as predicted in H3a $(\beta=-.042, p=.692)$. In contrast to Hypothesis $3 \mathrm{~b}$, positive affect did not predict relatedness at work $(\beta=.094, p=.295)$. In support with $\mathrm{H} 4$, inspiring affect predicted have focus $(\beta=.627, p<.001)$, which in turn predicted meaning at work $(\beta=.372, p<.001)$ and relatedness at work $(\beta=.311, p<.001)$ significantly. Have focus fully mediated the relationship between inspiring affect and meaning at work $(\beta=.233, p<.001,90 \%$ CI [.059 .407]) and relatedness at work $((\beta=.195$, $p<.001,90 \%$ CI [.057 .333]), supporting H5a and H5b. In contrast to H6a, positive affect $(\beta=.029, p=.750)$ did not predict vitality. However, inspiring affect did predict $(\beta=.365, p<.001)$ vitality, supporting H6b.

Fig. 1 
Path model of the hypothesized relationships (H1-6). Only significant standardized path coefficients are presented $(p<.05)$. Model fit was based on $\mathrm{Hu}$ and Bentler's (1999) recommended fit indices: CFI $>.95$, RMSEA $<.06$, SRMR $<.09$

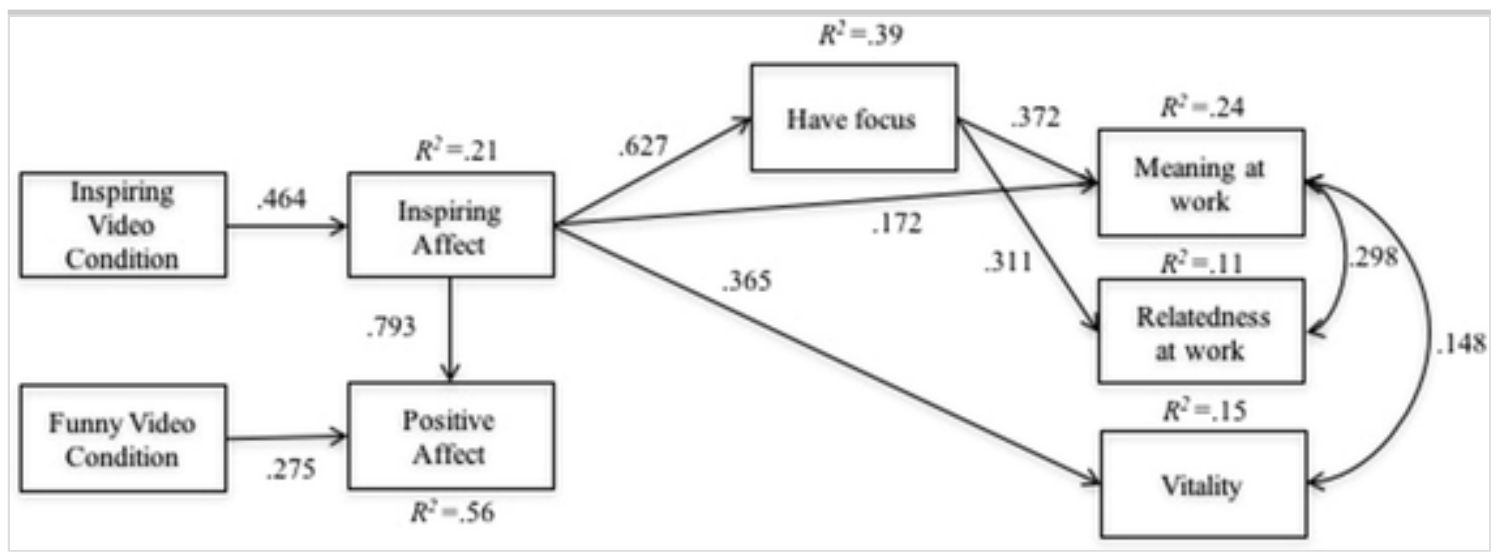

AQ6

To investigate $\mathrm{H} 7$ and RQ2, a repeated measurement MANOVA analysis was conducted across the four conditions between stress and vitality before and after the videos. At $\mathrm{t} 1$, none of the conditions differed significantly from each other in their levels of stress and vitality $(p>.05)$. The analysis revealed a non-significant interaction between conditions and stress at both time points [Wilks $\Lambda=.996$, $F(3,196)=.231, p=.875$, partial $\left.\eta^{2}=.004\right]$, but a significant main effect for stress between time points [Wilks $\Lambda=.651, F(1,196)=105.29, p<.001$, partial $\left.\eta^{2}=.349\right]$. A simple effects analysis showed significant decreases in stress after watching the video across all 4 conditions (see Table 3), leaving H7a unsupported. For vitality, a significant interaction effect between conditions and vitality at different time points resulted [Wilks $\Lambda=.862, F(3,196)=10.473, p<.001$, partial $\left.\eta^{2}=.138\right]$. Whereas the control condition did not show any significant differences in their pre-post vitality ratings $[t(57)=.796, p=.429]$, there was a significant difference between the vitality ratings in the elevation $[t(51)=5.97, p<.001]$, gratitude $[t(38)=4.98, p<.001]$ and fun condition $[t(50)=4.14, p<.001]$. A post hoc investigation (LSD corrected) of the means for vitality at 2 across conditions indicated a significant difference between the control group and the gratitude $(p=.029)$ and elevation group $(p<.001)$, but not the fun condition $(p>.05)$. The fun condition in turn was only significantly different from the elevation condition $(p=.004)$. There was no difference between the elevation and gratitude condition in their levels of vitality at $\mathrm{t} 2(p>.05)$. Consequently, $\mathrm{H} 7 \mathrm{~b}$ was partially supported. Our Research Question asked about the unique role of eudaimonic and hedonic entertainment for stress reduction and vitality increase. According to the results of 
the interaction effects, it becomes apparent that for vitality the elevating videos were more energizing in nature than the fun or the control videos. In contrast, stress reduction seemed to result from any type of media. Even a non-narrative slide show presentation of nature images (control condition) lead to a significant decrease in stress in participants (Table 4).

\section{Table 4}

Mean differences results of the repeated measurement MANOVA analysis comparing stress and vitality across two time points between conditions

\begin{tabular}{|c|c|c|c|c|c|c|}
\hline \multirow{3}{*}{ Condition } & \multicolumn{3}{|l|}{ Stress } & \multicolumn{3}{|l|}{ Vitality } \\
\hline & \multirow{2}{*}{$\begin{array}{l}\text { t1 } \\
M(S D)\end{array}$} & \multirow{2}{*}{$\begin{array}{l}\mathbf{t 2} \\
M(S D)\end{array}$} & \multirow{2}{*}{$\begin{array}{l}\text { Cohen's } \\
d\end{array}$} & t1 & t2 & \multirow{2}{*}{$\begin{array}{l}\text { Cohen's } \\
d\end{array}$} \\
\hline & & & & $M(S D)$ & $M(S D)$ & \\
\hline Elevation & $\begin{array}{l}50.98 \\
(22.93)\end{array}$ & $\begin{array}{l}38.80 \\
(22.78)\end{array}$ & $.655^{* *}$ & $\begin{array}{l}4.56 \\
(1.62)\end{array}$ & $\begin{array}{l}5.41 \\
(1.46)\end{array}$ & $.852 * *$ \\
\hline Gratitude & $\begin{array}{l}52.38 \\
(22.99)\end{array}$ & $\begin{array}{l}38.46 \\
(23.59)\end{array}$ & $.638 * *$ & $\begin{array}{l}3.93 \\
(1.59)\end{array}$ & $\begin{array}{l}4.93 \\
(1.37)\end{array}$ & $.809 * *$ \\
\hline Fun & $\begin{array}{l}48.48 \\
(23.68)\end{array}$ & $\begin{array}{l}33.90 \\
(22.18)\end{array}$ & $.805^{* *}$ & $\begin{array}{l}3.95 \\
(1.69)\end{array}$ & $\begin{array}{l}4.53 \\
(1.66)\end{array}$ & $.584 * *$ \\
\hline Control & $\begin{array}{l}45.11 \\
(24.41)\end{array}$ & $\begin{array}{l}30.10 \\
(22.67)\end{array}$ & $.840 * *$ & $\begin{array}{l}4.34 \\
(1.45)\end{array}$ & $\begin{array}{l}4.22 \\
(1.61)\end{array}$ & .105 \\
\hline
\end{tabular}

Cohen's $d$ is corrected for dependence between means using Morris and DeShon's (2002)

Eq. 8. $p$ value for the insignificant coefficient between vitality t1 and t 2 is $p=.429$

Stress/vitality $t 1$ stress and vitality before the video, Stress/vitality $t 2$ stress and vitality after the video

$* * p<.001$

AQ7

\section{Discussion}

The goals of the present study were (1) to investigate the role of eudaimonic and hedonic media on stress reduction and well-being of employees in a real world setting, (2) to extend previous work on the effects of eudaimonic and hedonic media on well-being by exploring the impact of specific affective experiences, namely, positive affect, elevation and gratitude, and (3) to extend previous work on media's impact on a broader range of well-being indicators at work, namely, psychological well-being through perceived meaning at work, subjective well-being through vitality and social well-being through perceived relatedness at work. 
Additionally, this paper further acknowledges the inspirational function of certain entertainment media by introducing appreciation of the good things in life as an explanatory variable between eudaimonic entertainment experiences and psychological and social well-being.

First, the manipulation check indicated that the inspiring media conditions did not differ significantly in positive affect from the fun condition. These findings are consistent with other studies on eudaimonic media (i.e., Oliver and Bartsch 2011; Oliver and Raney 2011; Rieger et al. 2014). Those studies understand elevation to specifically include mixed affect, which means to experience positive and negative emotions at the same time. In our study, inspiring media was perceived as similarly emotionally positive as funny media, while at the same time as significantly more negative than funny media. Thus, our data supports previous research on the uniqueness of eudaimonic (or inspiring) media content as funny and sad at the same time.

Second, both, the gratitude and elevation condition differed significantly from the fun and control condition in their elicitation of elevation and gratitude, indicating that eudaimonic media experiences are indeed different from funny or neutral media when it comes to their elicitation of inspiring affect (i.e., elevation, gratitude. Oliver and Bartsch 2011; Wirth et al. 2012). The experience of gratitude as elicited from media stimuli is still at its infancy. Our data suggests that gratitude and elevation are highly correlated. So far, the studies that have been conducted on elevation in the field of media psychology (i.e., Oliver et al. 2012; Janicke and Oliver 2017; Ellithorpe et al. 2015) never measured gratitude as another additional experience to elevation that results from portrayals of moral beauty and excellence (Algoe and Haidt 2009). However, when investigating inspiring videos, not only do they portray altruism and thus, elicit elevation, they also often portray another source intentionally improving someone's-well-being, which is what Fredrickson (2004) described as an elicitor of gratitude (see also Dale et al. 2017). Therefore, it is not surprising to find elevation and gratitude to coincide in specific inspiring media portrayals. Our data suggests that eudaimonic videos can be mainly elevating, or can be elevating and eliciting gratitude in the same way. Whether media can also solely elicit gratitude without the experience of elevation still needs to be explored. So far, our study indicates, what has been reported before (Algoe and Haidt 2009; Diessner et al. 2013): that gratitude may not be completely differentiable from elevation. Future research may profit from an investigation of gratitude experience in addition to elevation as elicited from media, in order to get a better understanding of an audience's eudaimonic media experience. 
As outlined earlier, both elevation and gratitude come from the family of selftranscendent emotions (also referred to as moral emotions), which are emotions that do not concern the self, or goals of the self, but a loss of ego and include an openness to others (Algoe and Haidt 2009; Haidt and Morris 2009). Since elevation and gratitude correlated highly, we combined the two scales into one, measuring, what we referred to as, inspiring affect to reflect the self-transcendent nature of the two emotions. Our model shows that inspiring affect, as elicited by inspiring but not funny videos, is the sole direct as well as indirect predictor for all three aspects of well-being as investigated in the current study: subjective well-being (operationalized with vitality), psychological well-being (operationalized as meaning at work), and social well-being (operationalized as relatedness at work) (see also Keyes 1998).

Furthermore, our results indicate a unique power of eudaimonic media compared to hedonic media to remind people of the "haves" rather than the "have not's" in life, supporting Adler and Fagley's (2005) assumption that appreciation for the positive aspects of life can be elicited through external triggers, such as media, for example. In addition, being reminded about one's haves in life reinforces the selftranscendent attributes of the eudaimonic media experiences. That means, feeling elevated and grateful after watching an inspiring Youtube clip makes people outward oriented and turned towards the larger aspects of life, such as being content with what one has, appreciating things such as health, family and friends and feeling fortunate about one's privileges and opportunities one has encountered in life ("Have" subscale items, Adler and Fagley 2005). Subsequently, this reminder about one's life's blessings translates into a greater perceived meaning at work, which in turn is associated with a positive experience of growth and purpose (Steger et al. 2012), as well as relatedness at work. It is the specific appreciation for the good things in life as elicited by inspiring affect, that contributes to the social wellbeing indicator of relatedness at work, but not inspiring affect per se, as predicted, indicating that the specific transcendent attributes of inspiring content are responsible for psychological and social well-being outcomes.

As related to meaning at work, these findings support what Sheldon and Lyubomirsky (2006) hypothesized before: being primed on gratitude and elevation through a short inspiring Youtube video, which include the activation of central values, purpose and competence, among others (see Wirth et al. 2012), seems to make employees aware of their life's fortune and privileges (have focus), 
potentially even interpret any negative circumstances at the work setting in a positive light, and thus contributing to an overall experience that one's work is meaningful. The experience of meaning at work has been associated, for example, with greater career commitment, less days absent from work and less psychological distress (anxiety, hostility, depression) (Steger et al. 2012). Thus, just a short eudaimonic entertainment experiences as elicited from a 3-5 min Youtube video at work can impact short-term psychological well-being (i.e., meaning at work), and potentially contribute to a range of positive health outcomes for employees in the long term. On the other hand, the experience of joy and delight from watching a funny video does not have the same effect on one's appreciation for the positive things in life and, in turn, one's perceived meaning at work. Future research is warranted to investigate these implications further.

As the findings relate to relatedness at work, appreciating the positive things in life refers to the interpersonal level of social functioning. That is, one's mind is directed away from the self towards others. Social well-being is the degree to which individuals master social challenges and are functioning well alongside their coworkers and other people they interact with in the world (Gallagher et al. 2009). It is a form of well-being that focuses on interpersonal relationships, whereas subjective and psychological well-being focus on the intrapersonal realm (Keyes 1998). Thus, it is reasonable to find a relationship between appreciation for the good things in life and feeling close to one's coworkers, as our data shows.

Contrary to our predictions, positive affect did not predict relatedness at work significantly. These results support previous research by Ryan et al. (2008) who counted (work) relatedness to be more closely associated with psychological wellbeing, but not subjective well-being. However, as noted before, because of the nature of inspiring media to be perceived as emotionally positive as well, we cannot exclude that positive affect does not play a role at all in people's perceived closeness to their co-workers. In fact, it may be a unique combination of positive affect, which has been related to approach tendencies (Carver and White 1994), and self-transcendent emotions (elevation and gratitude), which orient people toward their colleagues. From the data at hand, we can conclude, however, that solely feeling happy and joyful does not impact people's perceptions about their co-worker relationships.

Moreover, in contrast to our hypothesis, we did not find a relationship between positive affect, as elicited from hedonic entertainment (Oliver and Bartsch 2011) and vitality, as an indicator of subjective well-being (Ryan and Deci 2001). 
However, we did find a direct relationship between inspiring affect, as elicited from eudaimonic media, and vitality, supporting previous research findings that showed a relationship between trait eudaimonia and vitality, for example (Huta and Ryan 2010) or a relationship between negative (but not purely positive) movie scenes and vitality (Rieger et al. 2017). Additionally, purely positive valence (as elicited from hedonic media fare) may not be enough to reduce tiredness (increase vitality) in participants. Instead, the more complex and demanding nature of inspiring media is more likely to increase one's arousal after successfully mastering the experience (Rieger et al. 2014). These findings furthermore indicate that eudaimonic media may not solely be related to psychological well-being, as previously predicted, but to subjective well-being as well. This is supported by our pre-post analysis of vitality, which showed a greater vitality increase from eudaimonic video clips (especially elevating videos) than funny videos or the control condition.

Whereas the results of Hypothesis 7a show that any form of media, even a neutral non narrative based slide show (control condition), reduces stress in employees, eudaimonic media seems to be especially energizing in nature, even more so than funny cat videos, as Gall Myrick (2015) found. The precise relationship between eudaimonic media and psychological and subjective well-being indicators remains to be explored. However, our data demonstrate that inspiring media may have a unique potential when it comes to recovering from work stress, and boosting employees' energy levels, meaning at work and co-worker relatedness. By that, our findings complement previous research on the positive effects of cyberslacking at work (i.e., Garrett and Danziger 2008a; Lim and Chen 2012), suggesting that watching inspiring videos at work can benefit employees well-being.

\subsection{Limitations and Future Research}

Since this is one of the first studies that investigated specific eudaimonic and hedonic affective experiences from Youtube clips at a workplace on people's stress levels and well-being indicators, it does come with some limitations.

First, as with any cross sectional data, the causality of our findings cannot be established. The assumed directions of our paths are based on previous studies (i.e., Rieger et al. 2014, 2015) and a result of a lack of longitudinal studies. However, the external validity of our design - due to real life circumstances instead of laboratory settings and employing an employee sample — can be regarded as an advantage of the chosen approach. It would be beneficial for future research to replicate our study assessing on which day of the week the study was taken, to control for potential blue Monday or happy Friday effects. 
Second, even though we used two videos per condition, the stimulus material is still limited in its scope. As our manipulation check indicated, the two inspiring media conditions were not perfectly distinguishable from the fun condition in their elicitation of positive affect. Future research is warranted to investigate an even broader variety of videos and to separate the experimental manipulation more clearly.

Additionally, we only compared different types of videos but did not include a nomedia control condition. This was done because previous research compared media conditions to a no-media control condition and found media to be more beneficial in terms of recovery, vitality and cognitive performance (Rieger et al. 2014, 2017). Further, basic research found that 'no distraction' control conditions can produce diverse results because people in general do not enjoy 'doing nothing' and engage in very distinct rumination, wondering, thinking etc. scenarios (Wilson et al. 2014). From a more applied point of view, it is very unlikely that employees would take breaks from work in which they would literally do nothing but sit still and relax. Taking these considerations into account, we decided to employ several media conditions and compare them. Thereby, however, this study cannot answer the question how different (non-mediated) break fillers could contribute to well-being. Based on Attention Restoration Theory (Kaplan and Berman 2010) we would also expect a stress reduction response from participants taking a walk outside or look outside a window into nature. Future research is warranted to investigate the relative value of media versus non media breaks for stress reduction and well-being.

Third, the indicators for psychological, subjective and social well-being only reflect a proportion of the overarching well-being concepts. One of the reasons for why we did find a relationship between inspiring affect and vitality may be that vitality is not a distinct indicator of subjective well-being. This also relates to our operationalisation of vitality: In line with previous research, we employed the tiredness subscale (see Reinecke et al. 2011; Rieger et al. 2014). As Ryan and Frederick (1997) point out, vitality is composed of psychological as well as somatic elements. Since we only assessed one dimension, namely that of subjective feelings of activation (reversely coded tiredness), we cannot draw conclusions about other vitality components. Future research is warranted to extend the exploration of different well-being indicators further, for instance by assessing the vigor dimension of vitality (see Schaufeli et al. 2006).

Fourth, due to time constraints, our study did not assess any personality variables such as trait positive affect or employees general stress levels which could further 
moderate the results. Future research would benefit from a more comprehensive analysis of moderator and personality variables to build a comprehensive picture how and for whom online videos at work contribute to well-being.

Lastly, knowing about the relevance of well-being in the workplace for employees' health and productivity, it remains to be seen how repeated exposure to, for example, specific inspiring videos (videos that elicit self-transcendent emotions such as elevation, gratitude or awe (Algoe and Haidt 2009) at the workplace), translate into long term well-being, reduction of sick leave, work satisfaction and productivity, for example. Knowing about the prevalence of the consumption of online videos at work ( $84 \%$ in our sample), the amount of time people spend with such videos during work $(33.5 \%$ watched online videos more than 5 times a week in our sample), and the positive effects these videos (especially eudaimonic videos in our study) have on people's well-being, recovery, vitality and even cognitive performance (Reinecke et al. 2009a; 2011; Rieger et al. 2014, 2015), it is crucial to further explore its' effects on employees stress management, workflow and overall happiness.

\section{Conclusion}

In conclusion, our study shows that cyberslacking in the form of watching Youtube videos at work, especially elevating and gratitude inspiring videos, seem to have a generally positive impact on employees' well-being. Videos that are mainly inspiring in nature not only increase employees' energy levels, but they also remind them about the good things in life, which makes them experience their work as more meaningful and make them feel connected to their coworkers. On the other hand, purely funny videos seem not to have a direct or indirect effect on employees well-being. However, any form of media consumed over a period of 3-4 min seemed to significantly reduce employees' stress levels, pointing out the importance of media for recovery experiences at work (i.e., Reinecke et al. 2009a, 2011; Rieger et al. 2014). We hope this study provides further steps towards future research in the fields of organizational psychology, positive psychology and media psychology, highlighting the beneficial use of online videos at the workplace for employees' stress reduction and well-being.

AQ9

\section{Funding}

Funding was provided by John Templeton Foundation (Grant No. 55826). 


\section{Appendix}

Gratitude video 1: https://www.youtube.com/watch?v=0YLVBIT0GDQ.

Gratitude video 2: https://www.youtube.com/watch?v=ege3YJ_01H8.

Elevation video 1: https://www.youtube.com/watch?v=svzPm81T36o.

Elevation video 2: https://www.youtube.com/watch?v=-cyvIKccdSg.

Funny video 1: https://www.youtube.com/watch?v=adIG2-Hec6E.

Funny video 2: https://www.youtube.com/watch?v=v9oxyswY8fs.

\section{References}

Adler, M. G., \& Fagley, N. S. (2005). Appreciation: Individual differences in finding value and meaning as a unique predictor of subjective well-being. Journal of Personality, 73(1), 79-114.

Algoe, S. B., \& Haidt, J. (2009). Witnessing excellence in action: The 'otherpraising' emotions of elevation, gratitude, and admiration. The Journal of Positive Psychology, 4(2), 105-127.

Anderson, M. (2015, February 12). 5 facts about online video, for YouTube's 10th birthday. Retrieved July 11 from http://www.pewresearch.org/facttank/2015/02/12/5-facts-about-online-video-for-youtubes-10th-birthday/.

APA Report (n.d.). American Psychological Association. Stress in America. Paying with our health. Retrieved March, 2016 from https://www.apa.org/news/press/releases/stress/2014/stress-report.pdf.

Arnold, K. A., Turner, N., Barling, J., Kelloway, E. K., \& McKee, M. C. (2007). Transformational leadership and psychological well-being: The mediating role of meaningful work. Journal of Occupational Health Psychology, 12, 193-203. https://doi.org/10.1037/1076-8998.12.3.193.

Baard, P. P., Deci, E. L., \& Ryan, R. M. (2004). Intrinsic need satisfaction: A motivational basis of performance and well-being in two work settings. Journal 
of Applied Social Psychology, 34(10), 2045-2068.

Bartlett, M. Y., \& DeSteno, D. (2006). Gratitude and prosocial behavior: Helping when it costs you. Psychological Science, 17, 319-325.

Carver, C. S., \& White, T. L. (1994). Behavioral inhibition, behavioral activation, and affective responses to impending reward and punishment: The BIS/BAS Scales. Journal of Personality and Social Psychology, 67(2), 319.

Chancellor, J., Layous, K., \& Lyubomirsky, S. (2015). Recalling positive events at work makes employees feel happier, move more, but interact less: A 6-week randomized controlled intervention at a Japanese workplace. Journal of Happiness Studies, 16(4), 871-887. https://doi.org/10.1007/s10902-014-9538-z.

Coker, B. L. (2011). Freedom to surf: The positive effects of workplace internet leisure browsing. New Technology, Work and Employment, 26(3), 238-247.

Conrad, A., Mueller, A., Doberenz, S., Kim, S., Meuret, A. E., Wolburg, E., et al. (2007). Psychophysiological effects of breathing instructions for stress management. Applied Psychophysiology and Biofeedback, 32(2), 89-98.

D'Abate, C. P., \& Eddy, E. R. (2007). Engaging in personal business on the job: Extending the presenteeism construct. Human Resource Development Quarterly, 18(3), 361-383.

Dale, K., Raney, A. A., Janicke, S. H., Sanders, M., \& Oliver, M. B. (2017). Youtube for good: A content analysis and examination of elicitors of selftranscendent media. Journal of Communication.

https://doi.org/10.1111/jcom.12333.

Deci, E. L., \& Ryan, R. M. (Eds.). (2002). Handbook of self-determination research. Rochester, NY: University of Rochester Press.

Diener, E. (1984). Subjective well-being. Psychological Bulletin, 95, 542-575.

Diessner, R., Iyer, R., Smith, M. M., \& Haidt, J. (2013). Who engages with moral beauty? Journal of Moral Education, 42(2), 139-163.

https://doi.org/10.1080/03057240.2013.78594. 
Eastin, M. S., Glynn, C. J., \& Griffiths, R. P. (2007). Psychology of communication technology use in the workplace. CyberPsychology \& Behavior, 10(3), 436-443.

Ellithorpe, M. E., Ewoldsen, D. R., \& Oliver, M. B. (2015). Elevation (sometimes) increases altruism: Choice and number of outcomes in elevating media effects. Psychology of Popular Media Culture, 4(3), 236-250. https://doi.org/10.1037/ppm0000023.

Emmons, R. A., \& McCullough, M. E. (2003). Counting blessings versus burdens: An experimental investigation of gratitude and subjective well-being in daily life. Journal of Personality and Social Psychology, 84(2), 377-389. https://doi.org/10.1037/0022-3514.84.2.377.

Faul, F., Erdfelder, E., Lang, A.-G., \& Buchner, A. (2007). G*Power 3: A flexible statistical power analysis program for the social, behavioral, and biomedical sciences. Behavior Research Methods, 39, 175-191.

Festinger, L. (1957). A theory of cognitive dissonance. Stanford, CA: Stanford University Press.

Fredrickson, B. L. (2001). The role of positive emotions in positive psychology: The broaden-and-build theory of positive emotions. American Psychologist, 56, $218-226$.

Fredrickson, B. L. (2004). Gratitude, like other positive emotions, broadens and builds. In R. A. Emmons \& M. E. McCullough (Eds.), The psychology of gratitude (pp. 145-166). New York, NY: Oxford University Press.

Fredrickson, B. L., Cohn, M. A., Coffey, K. A., Pek, J., \& Finkel, S. M. (2008). Open hearts build lives: Positive emotions, induced through loving-kindness meditation, build consequential personal resources. Journal of Personality and Social Psychology, 95(5), 1045-1062. https://doi.org/10.1037/a0013262.

Freeman, D., Aquino, K., \& McFerran, B. (2009). Overcoming beneficiary race as an impediment to charitable donation: Social dominance orientation, the experience of moral elevation, and donation behavior. Personality and Social Psychology Bulletin, 35, 72-84. 
Gall Myrick, J. (2015). Emotion regulation, procrastination, and watching cat videos online: Who watches Internet cats, why and to what effect? Computers in Human Behavior, 52, 168-176. https://doi.org/10.1016/j.chb.2015.06.001.

Gallagher, M. W., Lopez, S. J., \& Preacher, K. J. (2009). The hierarchical structure of well-being. Journal of Personality, 77(4), 1025-1050.

Garrett, R. K., \& Danziger, J. N. (2008a). Disaffection or expected outcomes: Understanding personal internet use during work. Journal of Computer-Mediated Communication, 13(4), 937-958.

Garrett, R. K., \& Danziger, J. N. (2008b). On cyberslacking: Workplace status and personal internet use at work. CyberPsychology \& Behavior, 11(3), 287-292.

Green, M. A., Brock, T. C., \& Kaufman, G. F. (2004). Understanding media enjoyment: The role of transportation into narrative worlds. Communication Theory, 14(4), 311-327. https://doi.org/10.1111/j.1468-2885.2004.tb00317.x.

Greenfield, D. N., \& Davis, R. A. (2002). Lost in cyberspace: The web@work. CyberPsychology \& Behavior, 5(4), 347-353.

Haidt, J. (2003). Elevation and the positive psychology of morality. In C. L. M. Keyes \& J. Haidt (Eds.), Flourishing: Positive psychology and the life well-lived (pp. 275-289). Washington, DC: American Psychological Association.

Haidt, J., \& Morris, J. P. (2009). Finding the self in self-transcendent emotions. Proceedings of the National Academy of Sciences, 106, 7687-7688.

Hu, L.-T., \& Bentler, P. M. (1999). Cutoff criteria for fit indexes in covariance structure analysis: Conventional criteria versus new alternatives. Structural Equation Modeling, 6, 1-55. https://doi.org/10.1080/10705519909540118.

Huta, V., \& Ryan, R. M. (2010). Pursuing pleasure or virtue: The differential and overlapping well-being benefits of hedonic and eudaimonic motives. Journal of Happiness Studies, 11(6), 735-762. https://doi.org/10.1007/s10902-009-9171-4.

Janicke, S. H., \& Oliver, M. B. (2017). The relationship between elevation, connectedness and compassionate love in meaningful films. Psychology of Popular Media Culture, 6(3), 274-289. https://doi.org/10.1037/ppm0000105. 
Kaplan, S., Bradley-Geist, J., Ahmad, A., Anderson, A., Hargrove, A., \& Lindsey, A. (2014). A test of two positive psychology interventions to increase employee well-being. Journal of Business and Psychology, 29(3), 367-380. https://doi.org/10.1007/s10869-013-9319-4.

Keyes, C. L. M. (1998). Social well-being. Social Psychology Quarterly, 61, $121-140$.

Lambert, N. M., Graham, S. M., Fincham, F. D., \& Stillman, T. F. (2009). A changed perspective: How gratitude can affect sense of coherence through positive reframing. Journal of Positive Psychology, 4, 461-470.

Lanham, M. E., Rye, M. S., Rimsky, L. S., \& Weill, S. R. (2012). How gratitude relates to burnout and job satisfaction in mental health professionals. Journal of Mental Health Counseling, 34(4), 341-354.

Lim, V. K., \& Chen, D. J. (2012). Cyberloafing at the workplace: Gain or drain on work? Behaviour \& Information Technology, 31(4), 343-353. https://doi.org/10.1080/01449290903353054.

Mastrangelo, P. M., Everton, W., \& Jolton, J. A. (2006). Personal use of work computers: Distraction versus destruction. CyberPsychology \& Behavior, 9(6), $730-741$.

McCullough, M. E., Tsang, J., \& Emmons, R. A. (2004). Gratitude in intermediate affective terrain: Links of grateful moods to individual differences and daily emotional experience. Journal of Personality and Social Psychology, 86(2), 295-309. https://doi.org/10.1037/0022-3514.86.2.295.

Morris, S. B., \& DeShon, R. P. (2002). Combining effect size estimates in metaanalysis with repeated measures and independent-groups designs. Psychological Methods, 7, 105-125.

Oliver, M. B., \& Bartsch, A. (2011). Appreciation of entertainment. The importance of meaningfulness via virtue and wisdom. Journal of Media Psychology: Theories, Methods, and Applications, 23, 29-33.

Oliver, M. B., Hartmann, T., \& Woolley, J. K. (2012). Elevation in response to entertainment portrayals of moral virtue. Human Communication Research, 38, 
Oliver, M. B., \& Raney, A. A. (2011). Entertainment as pleasurable and meaningful: Identifying hedonic and eudaimonic motivations for entertainment consumption. Journal of Communication, 61, 984-1004.

Park, N., Peterson, C., \& Seligman, M. E. (2004). Strengths of character and well-being. Journal of Social and Clinical Psychology, 23(5), 603-619.

Reinecke, L. (2009a). Games at work: The recreational use of computer games during working hours. Cyberpsychology \& Behavior, 12(4), 461-465.

Reinecke, L. (2009b). Games and recovery: The use of video and computer games to recuperate from stress and strain. Journal of Media Psychology: Theories, Methods, and Applications, 21(3), 126-142. https://doi.org/10.1027/1864-1105.21.3.126.

Reinecke, L., Klatt, J., \& Krämer, N. C. (2011). Entertaining media use and the satisfaction of recovery needs: Recovery outcomes associated with the use of interactive and noninteractive entertaining media. Media Psychology, 14(2), 192-215. https://doi.org/10.1080/15213269.2011.573466.

Rieger, D., \& Bente, G. (in press). Watching down cortisol levels? Effects of movie entertainment on psychophysiological recovery. Studies in Communication and Media.

$\mathrm{AQ} 10$

Rieger, D., Frischlich, L., \& Oliver, M. B. (2016, June). Self-construal and elevation-Intercultural differences in transported values through mass media content. Paper presented at the 66th Annual Conference of the International Communication Association, 09.-13.06.16, Fukuoka, Japan.

Rieger, D., Reinecke, L., \& Bente, G. (2017). Media induced recovery: The effects of positive versus negative media stimuli on recovery experience, cognitive performance, and energetic arousal. Psychology of Popular Media Culture, 6(2), 174-191. https://doi.org/10.1037/ppm0000075.

Rieger, D., Reinecke, L., Frischlich, L., \& Bente, G. (2014). Media entertainment and well-being-Linking hedonic and eudaimonic entertainment 
experience to Media-Induced recovery and vitality. Journal of Communication, 64(3), 456-478. https://doi.org/10.1111/jcom.12097.

Ryan, R. M., \& Deci, E. L. (2001). On happiness and human potentials: A review of research on hedonic and eudaimonic well-being. Annual Review of Psychology, 52, 141-166.

Ryan, R. M., \& Frederick, C. (1997). On energy, personality, and health: Subjective vitality as a dynamic reflection of well-being. Journal of Personality, 65(3), 529-565.

Ryan, R. M., Huta, V., \& Deci, E. L. (2008). Living well: A self-determination theory perspective on eudaimonia. Journal of Happiness Studies, 9, 139-170.

Ryff, C. D. (1989). Happiness is everything, or is it: Explorations on the meaning of psychological well-being. Journal of Personality and Social Psychology, 57, 1069-1081.

Schaufeli, W. B., Bakker, A. B., \& Salanova, M. (2006). The measurement of work engagement with a short questionnaire. Educational and Psychological Measurement, 66(4), 701-716. https://doi.org/10.1177/0013164405282471.

Seligman, M. E. P., Steen, T. A., Park, N., \& Peterson, C. (2005). Positive psychology progress: Empirical validation of interventions. American Psychologist, 60(5), 410-421. https://doi.org/10.1037/0003-066X.60.5.410.

Sheldon, K. M., \& Lyubomirsky, S. (2006). Achieving sustainable gains in happiness: Change your actions, not your circumstances. Journal of Happiness Studies, 7(1), 55-86. https://doi.org/10.1007/s10902-005-0868-8.

Steger, M. F., Dik, B. J., \& Duffy, R. D. (2012). Measuring meaningful work: The work and meaning inventory (WAMI). Journal of Career Assessment. https://doi.org/10.1177/1069072711436160.

Thayer, R. E. (1989). The biopsychology of mood and arousal. New York, NY: Oxford University Press.

Thrash, T. M., \& Elliot, A. J. (2004). Inspiration: Core characteristics, component processes, antecedents, and function. Journal of Personality and 
Social Psychology, 87(6), 957-973. https://doi.org/10.1037/0022-3514.87.6.957.

Vorderer, P. (2011). What's next? Remarks on the current vitalization of entertainment theory. Journal of Media Psychology, 23, 60-63.

https://doi.org/10.1027/1864-1105/a000034.

Wilson, T. D., Reinhard, D. A., Westgate, E. C., Gilbert, D. T., Ellerbeck, N., Hahn, C., et al. (2014). Just think: The challenges of the disengaged mind. Science, 345(6192), 75-77.

Wirth, W., Hofer, M., \& Schramm, H. (2012). Beyond pleasure: Exploring the eudaimonic entertainment experience. Human Communication Research, 38(4), 406-428. https://doi.org/10.1111/j.1468-2958.2012.01434.x.

Wood, A. M., Froh, J. J., \& Geraghty, A. W. A. (2010). Gratitude and wellbeing: A review and theoretical integration. Clinical Psychology Review, 30(7), 890-905. https://doi.org/10.1016/j.cpr.2010.03.005.

\footnotetext{
${ }^{1}$ Videos that potentially could elicit awe were included in the pretest. However, the results indicated that none of the videos elicited strong feelings of awe, nor did they differ from the other emotions, which is why we don't refer to this measure further in the pre-test description.

2 Please note that we will discuss this conceptual overlap between gratitude and elevation in the discussion because we believe that it has important theoretical implications.
} 